\title{
ALEJANDRO ROSSI: \\ LA FÁBULA DE LAS REGIONES
}

\author{
POR \\ Julio Ortega \\ Brown University
}

Alejandro Rossi (Florencia, 1932) es un gran escritor reluctante. En sus cuentos, ha imaginado la vida literaria como una de las versiones menores del infierno dantesco; pero ha reconocido también la magia posible de la escritura, su rara epifanía casual. Y así, fuera de los catálogos de la actualidad, incluso con un deliberado destiempo, como si se tratara de un malentendido metódico, ha ido dando a conocer su prosa de excepción y sus cuentos excepcionales.

Los tres delgados volúmenes de relatos que ha publicado parecen adelantos tardíos de otro volumen, que los incluye, no sólo porque los relatos del primero aparecen en el segundo, y uno del segundo reaparece en el tercero; sino porque todos ellos se leen como fragmentos que nos llevan de una pista a otra, de una zona de experiencia a otra de reflexión; y se suman al modo de una figura profunda, que nunca se completa, y que hace de la parcialidad su forma de elocuencia. Leer a Rossi es elegir una ruta en ese territorio arcaico y a la vez reciente, remoto y en formación.

Pero, de otra manera, al culminar este recorrido, fascinante e inquietante, nos damos con que hay otros volúmenes tácitos, la novela de una escritura fragmentaria, detrás de estas colecciones resumidas. Incluso en su celebrado Manual del distraído ( $1^{\mathrm{a}}$ edición 1978), donde reúne sus crónicas de varia reflexión, Rossi incluyó relatos que pertenecen a su "novela" de la vida literaria, la que otros cuentos completan a su modo. Ocurre, entonces, que la lectura noveliza la escritura de este narrador elusivo y a la vez inclusivo, quizá consciente de que cada cuento es una novela latente, cada crónica un relato biográfico, cada nota un ensayo improbable. Esta reducción formal de la promesa discursiva es, ciertamente, un ejercicio crítico que se remonta a la moderna autoconciencia del lenguaje; pero esta expansión novelesca de las tramas y los significados, esta contaminación narrativa de lo escrito, remite al carácter latinoamericano de una escritura de los recomienzos; según la cual todo puede estar, bien o mal, formulado salvo el lugar del sujeto en el lenguaje, y el de éste en la diferencia nuestra. En la narrativa de Alejandro Rossi, ese carácter es incierto, ese lugar es el de la identidad interrogada, y esa diferencia convoca la fábula de la pertenencia.

La escritura del recomienzo es el escenario de una narrativa hecha de polaridades íntimas, de una lucidez autoirónica, que narra no sin delectación su propia ocurrencia como si se tratara de un drama familiar y antiheroico. Así, lo que recomienza viene de 
lejos: los orígenes no son un mito adánico sino un discurso sobreescrito. La nueva escritura, la propia, que es de por sí ajena, debe "nacer", recomenzar, entre las páginas y los márgenes, con la ironía de su nacimiento público, la errancia de su registro incierto, y la intimidad asombrada de sus promesas incumplidas. Si todo lo que quedara de la narrativa fueran estos poquísimos textos de Rossi, desde ellos se podría reconstruir la historia universal de la literatura. Dado que todo está ya escrito (por Conrad, Stendhal, Borges ...) y casi todo está ya pensado (por Leibniz, Schopenhauer, Wittgenstein ...), sólo nos queda la perfección, esto es, el escepticismo clásico. Esa elegancia final es el culto de las formas gratuitas, y supone la ligera marginalidad del escritor, y el carácter a la vez desinteresado y definitivo de su trabajo.

Y, sin embargo, Rossi no se resigna a la lucidez. Está fascinado por la naturaleza errática de las cosas, por la textura temporal de los hechos, por la contradictoria trama de milagro y trivialidad que el lenguaje construye como casa no del ser sino del estar, de esa encrucijada. Y está, claro, intrigado por la fuerza pasional que acude al llamado de lo vivo: presencias y ausencias, inteligencia y bobería de la cotidianidad humana, redimida por el habla mutua, la memoria derivada, la belleza imprevista, la promesa heroica de la identidad marginal. Por eso, Rossi ha extremado su diálogo con la obra de Borges: es, en un sentido, el más borgiano de los escritores no porque siga el estilo puntilloso del maestro sino porque comparte con él la noción radical de lo imaginario como materia final; pero, en otro sentido, reescribe a Borges, llevándolo de vuelta hacia lo cotidiano y por otra dirección hacia la historicidad sin letra. Allí, en esa encrucijada, Rossi encuentra su propia escritura. Discutiendo la lectura de Borges ("La página perfecta", Manual del distraído) extrema, en efecto, la naturaleza literaria de lo escrito, al poner en duda el concepto de identidad de la obra ("elástico y precario"); pero no porque la tradición se reactualice en la página (los "precursores" borgianos) sino porque la página escrita se proyecta hacia un futuro escritor: "Soy, desde ahora, el epígono de un maestro inexistente, soy el representante de una escuela cuyo manifiesto desconozco" (22). Bien mirado, la pregunta que hace Rossi a Borges es por la otra identidad, la del autor/lector, enigma virtual, ya que si un libro "es un espejo" (125) en él no aparece la figura que compone el rostro de un autor, como pretendió, resignado, Borges, sino la más insólita cara del lector, a la que debo, horror, mi identidad. He ahí el camino propio de Rossi: el lector es una revelación del autor, y no por una complicidad hipócrita, según la fórmula sentimental de Baudelaire, sino porque esa participación del otro convierte en autobiográfica a la escritura. Si Borges escribió para borrar el yo, y sugerir un sujeto indistinto y sustitutivo; Rossi explora, en cambio, los límites del sujeto, que ya no son los del lenguaje, sino los del sinsentido, que el lenguaje no puede cambiar. Y la lectura, como un subtexto, trama los asombros de ese sujeto, entre la biografía y la historia, el absurdo y la cotidianidad, la fábula no escrita y la literatura que, como la vida, suele estar malescrita. Contar es leer (con lucidez) la magia (casual) de lo cotidiano (moderno y espeso); y, por lo mismo, es interpretar (buscar "la interpretación verdadera", proyecto poético) la suerte del sujeto entre los discursos (biográfico, histórico, literario) donde el lector lo aguarda, persuadido y conjurado. Para dejar de ser borgiano, Rossi lo fue plenamente; $y$, por eso, desde su primer cuento es ya es un escritor maduro y distinto, con la sabiduría casi perturbadora de la elisión, y el poder evocativo de una palabra (más que precisa, más que justa, inquietante) que estremece la 
superficie del idioma con su brío y su ingenio, con la breve zozobra que comunica tanto a la lógica como a la naturalidad del lenguaje.

Ahora bien, si Rossi reescribe los comienzos (de la misma escritura, de una América Latina incumplida, de una biografía del sujeto y su errancia) desde su incertidumbre y zozobra, y a nombre de la certeza probable que el relato interroga; esta peregrinación entre asombros y desconsuelos supone, a su vez, que la identidad del sujeto está amenazada por los discursos formalizados y socializados; y busca abrir un espacio simbólico representado por el habla arcaica de una historicidad no oficial, que se alimenta de la leyenda patricia, la oralidad de las regiones del interior, los territorios no cartografiados, donde la naturaleza y la historia ignoran las fronteras oficiales y poseen su propia identidad en la diferencia. Cada una de estas instancias de la escritura abre, de por sí, una novela potencial, un libro más grande dentro del breve libro de cuentos, hemos dicho; pero las tres dimensiones de esta escritura (a las que habría que añadir la cuarta dimensión reflexiva: los textos del "distraído", del pensador a pesar suyo) coinciden como distintas ampliaciones de una misma indagación, irónica y apasionada, por la naturaleza de la fábula, por el saber que promete y revela.

Sueños de Occam (México: UNAM, 1983; incluido en El cielo de Sotero, Barcelona: Anagrama, 1987, edición que manejo aquí) empieza con un relato emblemático de la obra de Rossi, "En plena fuga", donde el narrador se narra a sí mismo como personaje del discurso reflexivo del recuento; y este lugar del lenguaje en que se sitúa es a la vez privilegiado (posee toda la tradición del soliloquio confesional para representar su propia voz) y precario (borra toda fábula para desnudar el acto enunciativo de su voz). El "estar" se plantea como el escenario del "ser"; pero entre ambos no hay consecuencias, salvo esta actividad precisa y zozobrante que es el "decir" y que representa un "pensar". "Estoy sentado en un sillón" (11), empieza el relato, y este es un gesto de la contemplación, que se reitera en los cuentos de Rossi como el punto de vista no sólo de la reflexión (recuento) o del recuerdo (fábula) sino, más decisivamente, de la conversación: el lector está presente, del otro lado del monólogo, como el interlocutor (retórico) a quien se dirigen las preguntas sistemáticas del relato. Por eso, consigna la situación de habla como su propia escena: "Si alguien me viera así, tan quieto y tan modesto, creería que yo espero un milagro" (11); y esta autorreferencialidad señala el límite del sinsentido gracias a la ironía del lenguaje, porque, en efecto, la promesa de la contemplación es la abundancia del sentido. En seguida, declara el relato su página en blanco, allí donde debe recomenzar: "Yo pienso, con angustia y banalidad, que la vida se escapa" (11). Y el relato se anuncia: "Me interesan más las fisuras insidiosas de la vida cotidiana, obra de roedores, no de demiurgos" (12). La voz, no obstante su claridad, debe distinguirse de los discursos que la sitúan: "Escucho con desesperación el aparatoso monólogo, lucho contra esa voz espesa, jalea verbal que pretende inmovilizarme ..." (12). Así, esta reflexión se da como un contramonólogo, en el breve espacio donde el lenguaje se produce, antes de ser un discurso, cuando apenas es su emisión: “¿De dónde viene ese deseo imperioso de hablar?" (14). No hay respuestas: sólo "asombro y azoro". Así, el drama es el acto mismo de hablar ("decidir"), de tener que elegir entre las palabras y las cosas, como si el sujeto fuese un mediador, un usuario que confirmase su poder gracias a la memoria y el lenguaje; y no fuese, más bien, una parte del mundo, un pensamiento indistinto del lenguaje insuficiente. Todo huye y no hay explicaciones: el 
monólogo regresa a la primera evidencia, pero ahora como una interrogación: “¿dónde estoy yo?" Y la respuesta traza otro límite del sinsentido, ese borde abismal desde donde se escribe: "Sentado en un sillón, rodeado de oscuridad, monarca de un mundo en plena fuga" (17). La intensidad del drama y la ironía absurdista que lo refiere, son una suerte de balbuceo del sentido, exasperado por la zozobra de lo vivo.

"De paso" es una secuencia de fragmentos así mismo reflexivos, uno de los cuales (32-33) complementa la actitud oposicional y opcional del pensar de lo fugaz en el primer relato. Esta vez se trata de una sátira ingeniosa del escéptico mundano, personaje cuyo descreimiento lo convierte en sujeto de un discurso tradicional (el del carpe diem, suponemos). "Lo invade una tristeza gozosa y, en ocasiones, la tentación del epigrama." Se trata, claro, de una "simpleza", a la cual, sin embargo, no se puede oponer sino "otra" (un poco menos simple, eso sí): "creer en algo —es decir, convencerse de una verdad y aceptar sus concecuencias - cuesta, es una lucha, es una conquista". No creer o creer son énfasis del discurso, pero su distinto valor está en los sujetos: uno es un diletante, el otro un desesperado. El hablante (el pre-narrador, se diría) en cambio es un escéptico que cree, con autoironía, estoicamente.

"Sueños de Occam" pertenece también a esta dimensión autorreflexiva que dramatiza el nacimiento del sujeto. Frente al nuevo día, el narrador se define: "no entiendo bien esa escenografía teológica ... Nunca sé si debo caer de rodillas o asociarme a un coro victorioso" (49). Esta vez, para actuar su reflexión, para decir su opción, demostrando "la posibilidad de otro destino", el narrador enumera la serie desiderativa de actos potencialmente disponibles; sólo que la vida parece proliferar en actos inmotivados y nos impone una laboriosa trama de "movimientos inútiles". Así, lo trivial sería lo naturalmente humano, y vivir con decoro exigiría darle una forma a ese espesor. "¿No es una gloria completar un movimiento?", se pregunta el narrador, "¿No es una gloria prepararse, sin angustias, a rendir cuentas?" (52). Ésta es una parodia absurdista de las ideas de Occam, seguramente de su discusión sobre las conexiones casuales entre una cosa y otra, que sólo creyó posibles en el mismo espacio y tiempo, como un fenómeno observable, concomitante e inferible. Ese escepticismo robusto y sistemático sólo demuestra la zozobra de los hechos humanos, infiere a su vez Rossi, aunque el relato sería la frágil posibilidad de una imagen que fuese una forma. Si no el sentido, al menos la forma: esa nostalgia alienta aquí, dando al lenguaje analítico un pathos cierto, gracias a la hipérbole misma. Esta práctica de la inferencia heterodoxa, de la reducción paradójica, de la demostración por el absurdo, remiten a la formación filosófica de Rossi, emparentada al logicismo de Wittgenstein, a sus reducciones interrogativas. Y pone a prueba la función conectiva del lenguaje al recomenzar por el acto de habla como la escena primaria de la fábula. De los sueños de Occam al despertar del sujeto, el relato recomienza no menos fantástico pero más incierto.

En El cielo de Sotero, "Diario de guerra", otra serie fragmentaria, pertenece a esta misma "novela del relato". "Es un fastidio reconocerlo, pero yo soy supersticioso. El mundo - ¿no lo sabía usted? — es de una fragilidad indignante" (69); este comienzo declara ya las polaridades: yo/mundo, y subjetividad/precariedad; que son antítesis homólogas. Frente a la fragilidad de lo real se explica la irracionalidad del sujeto; y sólo la subjetividad del yo podría interpretar la relatividad del mundo. Ante la autoridad de la razón y sus discursos, que encarnan el profesor y el padre, las dos figuras patriarcales del discurso (los 
frailes jesuitas son otra, recurrente), esta reflexión, animada por el sarcasmo, subvierte los términos y proclama que "tocar madera" es un conjuro y una conjura. Después de todo, si la realidad es arbitraria, incalculable y episódica, este acto irracional puede, en efecto, evitar "los lejanos ciclones". Si la teoría del caos puede reemplazar a "La vieja teoría de la correspondencia" (72), y si el sujeto prefiere que el árbol no sea un signo sino sólo árbol, para "acariciarlo sin ninguna responsabilidad semántica y ontológica", la mujer, en cambio, o por lo menos su fácil emblema, Patricia, la pintora teórica del segundo fragmento, le añade explicaciones a las cosas; pregunta, previsiblemente, si "los pájaros conversan entre ellos". El narrador lo duda, y esa duda lo revela. Del arte no espera una indulgencia comunicativa sino una reducción expresiva, una economía de signo inverso a la discursividad del relato. Esta página es, así, un manifiesto contra Proust: frente a la proliferación de los personajes que charlan como bellos insectos que intercambian el polen fecundo, Rossi prefiere la "precisión del movimiento de los pájaros" que contrasta con nuestras "conductas inútiles". En cambio, un pastor alemán "altanero y tierno", que el narrador tuvo, parecía un "exiliado lleno de abulia y de recuerdos", y vivía "perpetuamente insatisfecho" antes del lenguaje y a pesar de la comunicación.

Reveladoramente, esta reflexión irónica sobre la escritura se convierte en una pregunta desasosegada por el yo. Tratar de escribir en el jardín, por ejemplo, exige situar al yo de la escritura en ese escenario: dado el contexto, ese yo tendría que ser otro, un general inglés retirado que escribe sus memorias, por ejemplo (78). O sea, soy el contexto desde donde me enuncio como sujeto de la escritura. Estar aquí, otra vez, es escribir allá: "¿Qué hago, entonces, aquí?" (79), se pregunta el narrador, porque esta nota que escribe es acerca del relato que no escribe. "Leo y de vez en cuando pretendo escribir", escribe, resignado al lenguaje de Patricia, natural y fluido, comunicación pura. El siguiente fragmento se rinde a las evidencias: no soy este ni aquel otro, por lo tanto, no soy un sujeto situado en el discurso, novelesco, capaz de escribir. Escribir, aparentemente, demanda decidir sobre el yo, optar por un sujeto, darse al lenguaje de las inferencias falaces. Después de todo, este narrador ha declarado (en "Regiones conocidas", Manual del distraido 129) estar "alarmado ... por el número enorme de palabras que caben en una cuartilla". Y no se trata de un problema de bloqueo literario, ni mucho menos de la desconfianza borgiana en la discursividad redundante de la novela; se trata de encontrar algo "absolutamente gratuito" (82) que decir. Se interroga el narrador: “¿No es de alguna manera humillante que jamás saltemos sobre nuestra historia personal, que siempre haya antecedentes y razones para decir lo que decimos?" (82). Se trata, entonces, de trascender el yo en el sujeto del relato, y la identidad de éste en la de la fábula. "El deseo profundo de escribir una prosa noble y clara, agua fresca, una prosa tranquila y convincente, con olor a buen manantial, con sabor a piedras de montaña alta, a tierra de pinares. Agua para beber. Y la convicción agotadora de que pertenezco a una generación enamorada de minucias, incapaz, me parece, de inventar un mito poderoso o un símbolo de la condición humana. No, no estoy desesperado, Patricia, estoy más bien impaciente" (85-86). Así, desde este estar en la prosa del mundo (como si el mundo estuviese palabra por palabra en una página de Thoman Mann); y desde este estar en el discurso incrédulo de los relatos totalizadores, el narrador reconoce tanto la promesa del lenguaje transparente (capaz de una comunicación restitutiva, reparadora) como la imposibilidad crítica de las explicaciones globales. Situado en su propia impaciencia, sólo al final del relato está listo para empezar a escribir. 
Claro que empezar es otro mito. No sólo porque todo está ya contado y sobredicho sino porque situarse en el cuento es recomenzar la vida literaria. Pocos escritores como Rossi han visto con más horror la república de las letras, la única donde no hay policías pero donde no pocos ejercen una vocación policiaca. Pero el problema no es solamente el ridículo de los poderes en disputa, esa exacerbada banalidad que distingue a los letrados menores. Más interesante es el problema de la sociabilidad de la letra. Esto es, la escritura parece hecha para consolidar los poderes dados, las ideas recibidas, las reparticiones injustas. $Y$, en fin, la misma literatura parece condenar al autor a una especialidad confusa, arbitraria y laboriosa. Rossi, que rechaza llamarse filósofo, y que prefiere verse como "una persona que piensa" (Manual del distraído 114); se concibe, sin duda, como un narrador, y más generalmente como un intelectual; pero sería una violencia clasificarlo en uno u otro grupo literario, tendencia de estilo, y hasta literatura nacional. Su independencia es otro rasgo de su identidad imaginaria, aunque también es evidente que concibe la literatura como una de las formas superiores de la conversación y la amistad.

Ya "Entre amigos" (en El sueño de Occam) plantea este dilema de empezar a escribir: el "sitio en que debe aparecer por primera vez" el pobre Da Silva, un compañero de aula, es la rutina escolar. Situado en su propio género ("Los buenos cuentos, me han dicho, comienzan en un lugar definido"), el relato sitúa en seguida al personaje. Ver, percibir, observar, refiere la actualidad de escribir: los muchachos se cuentan mutuamente historias como si fueran personajes de grandeza improbable pero suficiente; sólo que Da Silva (marginal al grupo, vulnerable) posee una mentira mayor: ha sustituido su identidad por la de un apellido reputado, y reparte las falsas tarjetas de visita. El lenguaje, así, crea la identidad, aunque precaria, social. Típico "chivo expiatorio" del grupo, Da Silva, doloroso y patético, es otro enigma del pasado: no hay una "interpretación justa" ahora. El dilema es el lugar de Da Silva en el recuento: si "deja de ser nuestro espejo" es porque "también deja de ser nuestro compañero".

Si ese relato sugiere las dimensiones morales de escribir, el juicio sumario de la escritura basada en la memoria; cuentos como "Los fantasmas de Leñada" en el mismo tomito, "Un café con Gorrondona" en El cielo de Sotero y los cuatro relatos finales de Manual del distraído (que podrían ser los primeros de la serie) completan esta segunda dimensión de los relatos de Rossi, los dedicados al círculo infernal de la profesión de las letras. "Un café con Gorrondona" se puede leer como una sátira a la pretensión, típica de la república letrada, de los "maestros", jueces patriarcales. Presenta a Juan Gorrondona, un crítico truculento y mezquino, que ha sido profesor de los imberbes escritores del grupo, cuyos primeros libros, ligeramente monstruosos, despedaza con entusiasmo. En "Con Leibniz" (Manual del distraído), este crítico diserta sobre los temas "profundos" de la literatura hispanoamericana: "los velorios, las putas interesantes, las borracheras metafísicas, los burdeles cósmicos y los personajes que disimuladamente se suicidan a lo largo de cuatrocientas páginas" (158). Lo definen, "su progresiva miopía, su merecida soledad, su meritoria infancia proletaria" (164). Pero tras la sátira y el grotesco, estos relatos presentan un espacio cerrado, asfixiante, donde los escritores perpetúan la mala literatura, el juicio banal, la incivilidad. Todo hay que leerlo aquí al revés: Rossi ha invertido, en efecto, los valores, y ha construído un mundo feroz y atroz. De inmediato, ello evoca a Borges y Bioy Casares, a sus relatos paródicos de la vida literaria argentina. No sólo por la sátira a 
los pomposos que creeen que en la literatura hay caminos equivocados y caminos ciertos, los suyos; también por la pintura moral de la indulgencia y la licencia proliferantes. Este es un tema caro al modernismo internacional, cuya inspiración confuciana llevó a Pound a hacer equivaler la salud de la república a la salud de la prosa.

En la sátira de Rossi hay menos color local que en Biorges (también menos caricatura política) y hay, en cambio, un jocoso fustigamiento moral y estético, que parece provenir de Pope (The Dunciad consagra a la Diosa del Aburrimiento como patrona de la república de los malos escritores), de Byron (cuyo Don Juan es un sabroso ejercicio en el arte de injuriar); y, por cierto, a Flaubert, cuyos enciclopedistas de lo trivial, Bouvard y Pécuchet, son los modelos inocentes de Gorrondona. Contra las "ideas recibidas" que encarna el crítico monumental, el narrador de "Sin sujeto" aclara que para librarse de ellas, "hay que arriesgar la imperfección. La alcancé plenamente" (165). Este narrador es, claro, no sólo mediocre sino elocuente, y se complace de haber logrado lo que él mismo llama un "tedio seminal" (166). Traducido al húngaro, habla de su "Obra" con mayúscula, aunque nos asegura que "El fracaso cansa" (168). De su maestro, Gorrondona, "el hombre que me alejó del público", porque lo libró de lectores y "neolectores", concluye: "Nadie lo halagó, nadie lo corrompió, probablemente nadie nunca lo leyó" (176). Como buena sátira, ésta culmina en la fascinación de su tema; en efecto, Rossi cultiva aquí esa forma mayor del contrasentido: el escritor menor. Pero no solamente el "poeta menor" en la Antología sino el escritor consistentemente irredimible, laboriosamente malo. Estos escritores revelan la arbitrariedad del destino artístico y la irracionalidad implacable del cenáculo literario; resultan fascinantes a una entomología del grotesco, que los mira con buen humor impecable e implacable. Ese mundo es triste y sórdido, pero también profundamente humano en su apasionada y enconada desmesura prolija. Lo real está también hecho de esta fisura del sentido, por donde el lenguaje se extravía, y el contrasentido nos alerta.

Lo que podría ser una dimensión tercera de la escritura de Rossi tiene que ver con otra serie de relatos, probablemente los más intrigantes que ha escrito hasta ahora, que corresponden al espacio histórico geográfico de "las regiones". El primero es "El cielo de Sotero", magnífico cuento, que se abre por dentro como una novela histórica posible; o mejor aun, que se prolonga más allá de la escritura de la historia, hacia el discurso no codificado de la lucha antigua y presente por fundar una palabra del recomienzo político. Aquí se trata del asesinato de un líder natural, Sotero, por un muchacho primario, Remigio Maldonado, entrenado por la facción enemiga para el crimen político. Los hechos son procesados desde la tácita disputa entre los discursos de la historia y de la ficción: si la historia es igual al sujeto menos su biografia, porque le basta con los hechos, el relato se demora en el "minuto atroz" y se pregunta por el poder, por el "orden del mundo" que ese asesinato pone en duda. "Las crónicas proceden, por así decirlo, con pies de plomo, más atentas a la paz de esos pueblos dispersos que a la terribles - o irresponsables - verdades de la vida" (90). Así, mientras la historia reduce los hechos al acto episódico y fortuito, el relato debe ahondar en él. Si la historia escrita es "una extensión de la política", la ficción es la memoria del porvenir. Por eso, la historia está fechada aquí en el futuro: 1998; aunque los hechos tienen la resonancia política del siglo pasado, del período de las formaciones nacionales, se inscriben aquí, con ironía simétrica, en este fin de siglo, señalando así no que la historia se repite, sino que no ha sido aún escrita: la que existe es versión 
oficial o interpretación política, pero nos falta la que incluya todos los agentes y todas las voces; de esa historia por hacerse nos quedan pérdida y muerte. Al mismo tiempo, este cuento de las regiones tiene una ubicación arcaica, que es característica del universo interior, pre-moderno y rural, donde se forman los caudillos, se suscitan las disputas entre unitarios y federales, y se configura el discurso de la diferencia cultural y política latinoamericanas. Podría, por ello, ser una suma de las regiones argentinas y de los llanos venezolanos, antes de que las fronteras se hubiesen fijado, cuando el proyecto emancipatorio sigue siendo la modernidad liberal y democrática, esa contradicción en los términos, que en América Latina buscó formar la república. Pero no estamos, claro, ante una geografía histórica literal sino ante el espacio discursivo privilegiado por la historicidad nuestra: estas "regiones" de Rossi no requieren ser determinadas en un mapa porque desafian a los mapas como incompletos y mutilantes. De cualquier modo, los "Ideólogos de la Mazorca" son los que preparan a Remigio para el asesinato, y ese lema convoca de inmediato a la otra Mazorca, la infame de Rosas, que Sarmiento asoció a la "barbarie" y Echeverría retrató en "El Matadero". Esos "ideólogos" representan un fundamentalismo fanático, que les hace dueños de una verdad absoluta; encarnan el autoritarismo latinoamericano, cuya práctica es ayer y hoy la misma: hablar a nombre de la nacionalidad, la pureza, la patria para los pocos, y deshumanizar al supuesto enemigo, cambiarle el nombre, denigrarlo ... Esa práctica antidemocrática, típica de los caudillos corruptos en México como en Perú, en Chile como en Colombia, termina con la promesa de la vida republicana, que Sotero representa. El cuento, en ese punto, se plantea un dilema mayor: ¿qué hacer con la violencia? ¿Cómo reintegrarla al discurso del relato y al espíritu tutelar de la comunidad prometida por las "regiones"? Borges, ante un dilema paralelo, optó por fundir a los sujetos, y en el tema universal del traidor y del héroe encontró dos máscaras del mismo personaje. En esa inversión, hizo de la historia una agonía de la conciencia, y del sentido histórico una nostalgia del orden patriarcal perdido. Rossi, más cerca de este tiempo de disoluciones, exigido a responder por el recomienzo, imagina una solución más novelesca y ejemplar: Lorenzo Cruz (curiosamente, lleva el nombre del hijo de Artemio Cruz, que murió peleando por la República en la guerra civil española, y es la otra "cara" de su monstruoso padre) no es ya un personaje "histórico"; pero el narrador lo asume, "Aunque no haya pruebas", excediendo la escritura de la historia, abriendo otro camino en la ficción. Cruz decide educar al muchacho asesino: leer y escribir, esos instrumentos del texto de la historia, cambian ahora de manos. Se trata de "recomenzar" desde esta víctima histórica, que ignora su propio lugar en ella: paulatinamente, va descubriendo, en los libros que Cruz le pasa, la historia de las regiones, desde sus orígenes hasta sus crónicas. Lee las crónicas asombradas del sabio Antonio Regueiro (¿Antonio Raimondi?), historias militares de las "guerras federales" y acerca del general que se convirtió en "soldado del polvo". El polvo de la historia, se diría, borra las escrituras. Y todo se reescribe en esta lectura que culmina en las evidencias: "la verdadera patria son las regiones, no esas fronteras de tinta china creadas por la diplomacia" (96). En este programa de resocialización, el relato afirma el predominio cultural modélico de la "región" en contra de la ciudad (lo que contradice a Sarmiento y afirma a Martí), y concluye con el proyecto histórico de Sotero: la unidad de las regiones, porque "nuestra historia verdadera todavía no había empezado" (97). Remigio, en fin, entiende la enormidad de su crimen y al convertirse en discípulo 
paradójico del héroe, sólo le resta el alivio de su propia condena. Al final, prevalece "el sabor de una oportunidad perdida. La fabula de las regiones" (99). Esa conciencia trágica (histórica) se reconstruye, así, como relato virtual del pasado, como la fábula de la pertenencia.

En La fábula de las regiones (México: Equilibrista, 1988) Rossi reunió junto a esta meditación melancólica, otros dos, "La estatua de Camargo", en el cual el narrador vuelve a la región en pos de la historia de su primo, un "mártir de la democracia", según la historia oficial, y en verdad otra víctima propicia. Dice el viejo relator: "Yo los leo poco, aunque entiendo que el Colegio de Historiadores es una de las instituciones más cuidadas por nuestro gobierno. Entrar allí es un privilegio y un alto honor. La tarea de ellos, Don Fernando, es inventar la Patria, darle forma, jerarquizar el endiablado remolino de los acontecimientos, ordenar las innumerables opiniones que recorren, como pájaros extraviados, estas interminables regiones. Los escribas oficiales nos proponen una versión canónica en la esperanza, creo yo, de que la realidad al fin entre en razón y se ajuste a ella" (21-22). Frente a esa racionalidad de lo escrito, el informante asume la oralidad popular, donde la muerte del héroe involuntario es una estratagema siniestra para desatar la represión y ganar un mártir. La política ingresa así al espacio autosuficiente de las regiones, reescribiendo su historia como parte del autoritarismo faccionalista nacional.

"Sedosa, la niña", el otro cuento, narra las proezas de un abuelo patriarcal, último representante de los "varones fluviales", que lleva a la cama a la mujer de su nieto, la nueva maestra del pueblo, cuya historia didáctica y oficial es contradicha por este anciano mítico. Ahora que los hombres de las regiones se han vuelto "representantes del feudalismo residual de las zonas fluviales" han dejado de ser los héroes naturales. "Los historiadores son unos perros, Mariela" (47), concluye el viejo. Este relato lo confirma: si los discursos disciplinarios forman parte del estado nacional y del control político de la interpretación, la "fábula de las regiones" responde con el relato de su vasta fragmentación, de su cultura tradicional que cuestiona la retórica de las modernizaciones a sangre y fuego, proclamadas por los fanáticos intelectuales de la razón dominante. Ese relato es menos una causa que una convicción, más una moral que una política; pero es, sobre todo, el último territorio del afincamiento del lenguaje creativo, aquél que responde por la diferencia de la cultura en la identidad de los saberes y decires que nos dan la nobleza de un cuento y la dignidad de una morada. Así, el sujeto interrogante encuentra su lugar más propio: el de un mundo prometido e inacabado, aun por hacerse, donde afinca como la fábula de estas hablas.

Nacido en Italia, de madre venezolana, Alejandro Rossi pasó su primera juventud en Argentina; estudió filosofía en México, Inglaterra y Alemania, donde estuvo en el seminario de Martin Heidegger; eligió, después de una breve experiencia en Estados Unidos, vivir en México, donde ha sido profesor de filosofía. Este cosmopolitismo, sin embargo, no lo hizo un escritor menos raigal; y aunque nadie podría dudar de su identidad latinoamericana, que periódicamente le han hecho recordar los cónsules de este mundo (lo ha contado en "Crónica americana", Manual del distraído), también es cierto que en su caso más que de cosmopolitismo se trata de un largo exilio natural; a tal punto que su literatura bien puede considerarse como un adelanto de la biografía literaria del exilio, esa condición moderna del arte mismo. En los últimos años, Rossi ha sido recuperado para la literatura venezolana por el fervor crítico de José Balza, otro narrador entrañable y luminoso; y este fenómeno 
de reconocimiento es un nuevo capítulo de la vida novelesca de la letra de este autor, suerte de Nabokov latinoamericano que escribe en la lengua franca del español de esta orilla. Rossi pudo haber sido un escritor italiano pero también un filósofo académico, un prosista argentino y hasta un ensayista mexicano. Aunque probablemente México le ha permitido ser, a gusto, un extranjero. Ahora que la patria materna, lo ha elegido para su literatura, Rossi, al modo de un hijo pródigo de la letra biográfica, proyecta la recuperación de su propio linaje regional, presidido por la vida de su antepasado el general Páez, otro peregrino de una América Latina extraviada en la historia y ganada en la imaginación. 